\title{
Internet-Based Structural Characteristics of Sports Betting and Problem Gambling Severity: Is There a Relationship?
}

\author{
Hibai Lopez-Gonzalez ${ }^{1,2}$ (D) Ana Estévez ${ }^{2}$. \\ Mark D. Griffiths ${ }^{1}$
}

Published online: 16 January 2018

(C) The Author(s) 2018. This article is an open access publication

\begin{abstract}
With the adoption and popularization of internet-based platforms, sports betting has introduced new functionalities that transform the design of its products and therefore the way bettors interact with them. This study aims to explore the association between the use of new structural characteristics of online betting and gambling severity. Five characteristics are examined here: (i) live in-play betting; (ii) cash out feature use (as example of in-play betting in-built features); (iii) fantasy sports gaming; (iv) location of betting; and (v) device or platform used to make bets. A cohort $(N=659)$ of Spanish gamblers who had bet on sports during the previous year was recruited through an online survey. The results suggested that those bettors scoring higher on gambling problems also utilized more often such new structural characteristics, in a proportion not explained only by their higher overall gambling activity. Mobile betting was especially frequent among problem gamblers.
\end{abstract}

Keywords Sports betting · Gambling $\cdot$ Internet · Fantasy $\cdot$ In-play $\cdot$ Mobile phone gambling

The prevalence of online sports betting has increased in many different jurisdictions over the past few years (Gainsbury 2014; Rodríguez et al. 2017). Betting on sports amounts to $37 \%$ of

Hibai Lopez-Gonzalez

hibai.lopezgonzalez@ntu.ac.uk

Ana Estévez

aestevez@deusto.es

Mark D. Griffiths

mark.griffiths@ntu.ac.uk

1 International Gaming Research Unit, Psychology Division, Nottingham Trent University, 50

Shakespeare Street, Nottingham NG1 4FQ, UK

2 Psychology Department, University of Deusto, Bilbo, Spain 
the annual online gambling market in Europe (European Gaming and Betting Association 2016). However, from a public health perspective, sports betting as a distinctive gambling type is subject to distinctive risk factors but has been relatively neglected compared to other types of gambling (Wicker and Soebbing 2013), perhaps due to the relatively small proportion of sports bettors openly seeking help in gambling treatment centers (Estévez et al. 2017; JiménezMurcia et al. 2011).

Prevalence studies in Great Britain have shown evidence that gambling type, when controlled for other factors, is not a significant predictor of problem gambling (LaPlante et al. 2011). Others, while generally agreeing with that assumption, have added that gambling type is not as relevant as individual factors, but, more importantly for the present paper, gambling type-related structural characteristics of each individual game can make gambling types more or less susceptible of causing gambling-related harm (Griffiths and Auer 2013). Many scholars have argued that the online component, a new situational as well as structural characteristic of many gambling products, has transformed the interaction between gamblers and gambling, altering the why, how, where, and when of gambling-related harm (e.g., Gainsbury et al. 2015; Gainsbury et al. 2014; Gray et al. 2012; McCormack and Griffiths 2013; Nordmyr et al. 2014).

\section{A Brief Overview of Sports Betting}

Over the past decade, a number of studies have examined the composition and characteristics of sports bettors. Many of these studies are country-specific, with great preponderance of research coming from Australia (Deans et al. 2016a; Deans et al. 2016b; Gordon et al. 2015; Hing et al. 2017a; Hing et al. 2016; Sproston et al. 2015; Woolley 2003). Cross-sectional studies of Australian sports bettors have identified risk factors for gambling problems such as being male, young, never married, living alone or in a group household, and with higher level education (Hing et al. 2016). Also, Australian sports bettors with a language other than English as their mother tongue are more likely to engage in problem betting (Hing et al. 2017a). Australian sports bettors prefer simpler bets in which the odds are easier to estimate, particularly when placing bets for a winner. Conversely, bets on multiple events (i.e., "exotic" bets such as accumulators) are less favored by regular bettors (Gainsbury and Russell 2015). Research has also indicated that the placing of bets during a sports event (i.e., in-play) is associated with less planned behavior and problem gambling (Hing et al. 2016; Lamont et al. 2016).

In qualitative studies of Australians' sports betting behavior, researchers have posited that the overlapping of sports and sports betting cultures poses a risk (Deans et al. 2016b), especially for younger bettors and children who identify betting as a safe way of winning quick money (Pitt et al. 2016). Research into online sports betting, as opposed to more traditional forms of offline betting, suggests that online sports bettors perceive their gambling as more determined by their own skills, knowledge, and analysis and less by chance or luck (Gordon et al. 2015).

In several studies utilizing a dataset provided by the gaming operator $b$ win of almost 50,000 European gamblers, researchers identified some distinguishing characteristics concerning sports bettors. Those who bet in-play on sports (as opposed to those who bet before matches) were categorized more often as heavily involved gamblers (LaBrie et al. 2007). The prototypical bettor was a 31-year-old male who bet for longer periods of time than females. Another study conducted in 2013 with an online pool of 634 German bettors found that the average bettor was a 26-year-old male with a monthly income lower than $€ 1000$ (Gassmann et al. 2017). 
Because the studies on bwin data were conducted a posteriori, they did not include a measure for problem gambling and resorted to proxy measures to ascertain its incidence. For example, they examined the number of gamblers who closed their account reporting problems controlling their gambling behavior, resulting in $32 \%$ of bettors claiming this reason for leaving (LaBrie and Shaffer 2011; LaPlante et al. 2008). In other studies with bwin data, the authors administered the Brief Biosocial Gambling Screen (BBGS) to 1422 self-selected gamblers. Approximately one quarter of them $(27 \%)$ were identified as having gambling-related problems. More importantly, live in-play betting was one of the most recurrent characteristics of problem gamblers, even after controlling for gambling participation and gambling type (LaPlante et al. 2014).

Live features of sports betting such as in-play betting and "cash out" betting have been argued to make sports bettors more vulnerable to cognitive biases (Lopez-Gonzalez et al. 2017a; Lopez-Gonzalez and Griffiths 2017). In an experiment with 161 sports bettors from France, participants with time constraints in placing their bets resorted more frequently to heuristic processing instead of analytical processing, leading to theoretically less reasonable bets (d'Astous and Di Gaspero 2015). New forms of online betting such as fantasy gaming also encompass a heightened perception of control over one's own abilities (Griffiths 2017). In the USA, online sports betting is only fully legal in a small number of states. Fantasy gaming has arguably covered for much of the market opportunities left unexplored by bookmakers. This has ignited a big national debate concerning the categorization of fantasy sports as skillbased games or luck-based gambling (Griffiths 2017; Rose 2015). Research with 500 fantasy sports players demonstrated that these consumers share with gamblers many behavioral similarities (Dwyer et al. 2017). Another study found examining a sample of 1556 American college students from 2012 that $12.9 \%$ of males and $0.6 \%$ of females had participated in "for money" fantasy leagues in the last year, and that especially in women, a correlation was found between gambling-related problems and fantasy gaming (Martin and Nelson 2014). In another study of college students participating in fantasy sports, it was found that athletes were more likely to experience gambling-related harm than non-athlete students (Martin et al. 2016).

In Spain, one study with data from 2005 found that Spanish sports bettors had an average age of 43 years, similar to the UK, and 10 years older than Canadian bettors (Humphreys and Perez 2012). These data were collected before the popularization of online gambling in Europe. Online sports betting participation in Spain has increased significantly, especially since the 2011 regulation that provided bookmakers with a new legal framework to enter the market (Dirección General de Ordenación del Juego [DGOJ] 2017a). According to data from the DGOJ, live inplay betting accounts for approximately $70 \%$ of the money staked on sports bets in the country. This gambling method represents a big departure from traditional forms of betting such as football pools, in which the structural characteristics of the game (e.g., the delay between bet and reward) contributed to making sports bets less addictive products (Griffiths and Auer 2013). Recent research analyzing gambling disorder patients under treatment in a Barcelona area hospital (in Spain) compared online to offline sports bettors. The results suggested that online bettors made greater maximum bets, and incurred financial debts sooner than offline-only bettors, and that the debts tended to be larger (Estévez et al. 2017).

\section{The Present Study}

This study seeks to address the lack of research concerning the association between new structural characteristics specifically impacting on sports betting behavior (and absent from other gambling 
types) and the gambling severity that bettors experience. More specifically, the present study explores demographic and behavioral betting factors utilizing a Spanish cohort of sports bettors. The aim of the study was to identify the influence of new online betting structural characteristics and examine if problem gambling severity varied across such new features. Five features are examined here: (i) live in-play betting; (ii) cash out feature use (as example of in-play betting inbuilt features); (iii) fantasy sports gaming; (iv) location of betting; and (v) device or platform used to make bets. Besides these, other covariates are controlled, including discussing bets before bets, time devoted to betting, as well as demographic data.

\section{Methods}

\section{Participants and Procedure}

A market research company contacted around 1200 people from their panel of Spanish residents, who had reported in previous unrelated market surveys that they had previously bet on sports events. These individuals were emailed by the company in March 2017 asking them to participate in an online survey. Participants received a message informing them about the anonymity and confidentiality of their data and the identification of the universities carrying out the research. The message let them know that the survey related to sports betting but no further information was provided at this point.

Within the first $72 \mathrm{~h}$ that the survey was up and running, 848 individuals opened the link for the survey and clicked to accept that they would like to participate in the study. However, 139 of them did not answered affirmatively to the filter question (i.e., have you placed at least one bet on sports in the past 12 months?). The remaining 709 participants who answered "yes" continued to the questionnaire although a number of them dropped out at a later point. After cleaning the data for incomplete cases, the final sample comprised 659 sports bettors who had gambled on sports events during the previous year.

The mean response duration was $10 \mathrm{~min}$ and $31 \mathrm{~s}$ (trimmed at $5 \%$ on both ends to remove extreme outliers likely due to system malfunction). Respondents had to be at least 18 years of age to participate and be able to respond to the questionnaire in Spanish. The present authors did not set any limits or quotas to the market research company as to the constituency of the sample beyond the filter question. A minimum of $10 \%$ of female bettors was first discussed but that percentage was easily reached without any quota manipulation. Participants who filled the questionnaire, including those who dropped out prematurely, received points according to the remuneration criteria set by the recruiting company, which could later be exchanged for gifts. The study followed the guidelines of the Declaration of Helsinki and was carried out after obtaining approval from the research team's university research ethics committee.

\section{Measures}

Demographic Data Data regarding age, gender, occupation, cohabitation, and level of education were collected.

Problem Gambling Severity Index This instrument is a self-administered abbreviated version of the Canadian Problem Gambling Index, adequate for screening gambling severity among online participants (Gainsbury et al. 2016). The method has been previously used for 
assessing problem gambling levels among subsets of sports bettors (Hing et al. 2017b; Hing et al. 2016). The Problem Gambling Severity Index (PGSI; Ferris and Wynne 2001) comprises nine items, four of which assess problem gambling behaviors and five adverse consequences of gambling (Holtgraves 2009). Each item is rated by respondents on a 4-point scale from $0=$ never to $3=$ almost always. Final scores range from 0 to 27 and allow for the categorization of respondents into four exclusive groups: $0=$ non-problem gamblers; $1-2=$ low-risk gamblers; 3-7 = moderate-risk gamblers; and 8 and more $=$ problem gamblers. Cronbach's alpha indicated excellent reliability $(\alpha=.945)$ in the current sample of sports bettors. Only the deletion of item 3 of the scale suggested a very marginal improvement in reliability $(\alpha=.948)$, but the correlation of this item $(r=.626)$ did not suggest its removal.

Use of New Structural Characteristics Participants were asked to assess the frequency of their engagement in a number of behaviors in relation to their betting activity. Questions included how often they used the cash out feature, the frequency of their in-play betting as opposed to pre-game betting, and how often they had participated in fantasy sports games (this item did not discriminate between free or for money fantasy gaming, nor daily or season-long participation). Such questions were designed to investigate new behavioral characteristics of sports betting associated with the adoption and popularization of online betting that had been less studied in previous research concerning betting behavior. These items were assessed on a 5-point Likert scale ( $1=$ never; $2=$ sometimes; $3=$ about half of the time; $4=$ most of the time; 5 = always). Other behaviors were also assessed (e.g., how often they discussed with others before placing a bet). Similarly, a self-perceived measure of the time they devoted to sports betting was included using a four-point scale ( $1=$ less than $1 \mathrm{~h}$ per week; 2 = between 1 and $3 \mathrm{~h}$ per week; 3 = more than $3 \mathrm{~h}$ but less than $7 \mathrm{~h}$ per week; $4=$ more than $1 \mathrm{~h}$ per day). Additionally, participants were surveyed about their preferred location to bet on sports and their preferred device or platform of choice to bet. Both location and device were expected to be influenced by the predominance of online gambling among European bettors. The type of device included three responses: laptop/computer, mobile phone/tablet, or gambling venue.

\section{Analysis}

Four types of gambler were created on the basis of PGSI scores (i.e., non-problem gambler, low-risk gambler, moderate-risk gambler, and problem gambler) unless stated otherwise. PGSI scores were skewed, and therefore non-parametric tests were favored in analysis of the data. Mann-Whitney $U$ test was used for nominal binary independent variables (e.g., gender), while Kruskal-Wallis test was used for PGSI groups as the independent variable. In the cases where the independent and dependent variables were nominal (i.e., PGSI groups and sociodemographic data, excluding age), chi-square tests were conducted and adjusted residuals' $z$ scores of \pm 2 examined for statistical significance. Finally, Spearman's rho was employed to analyze interval data.

\section{Results}

Table 1 summarizes the main socio-economic results from the sample of sports bettors categorized according to their gambling severity group. Participants had a mean age of 35.1 years $(\mathrm{SD}=10.1$, 
range 18-66 years). The mean score for PGSI as ratio variable was $3.58(\mathrm{SD}=5.29$, range $0-27)$. Based on PGSI scores, the four categorical gambling severity groups comprised non-problem gamblers $(N=256 ; 38.8 \%)$, low-risk gamblers $(N=175 ; 26.6 \%)$, moderate-risk gamblers $(N=102$; $15.5 \%)$, and problem gamblers $(N=126 ; 19.1 \%)$. The sample comprised 489 males $(74.2 \%)$ and 170 females $(25.8 \%)$. As an independent variable, gender did not appear to be significantly associated with problem gambling severity (Mann-Whitney $U=39,394, Z=-1.050, p=0.294$ ). In fact, females showed a higher mean rank (342.77) than males (325.56) and were overrepresented in the most severe condition of problem gambling $(N=40 ; 31.7 \%$, as opposed to their $25.8 \%$ overall representation in the sample).

By level of education, participants ranged from less than complete high school education $(N=5,0.75 \%)$ and complete high school education $(N=114,17.2 \%)$, to at least vocational or technical education $(N=139,21.09 \%)$ and university education $(N=401,60.8 \%)$. No statistical significance was found in the distribution of problem gambling among these educational groups $\left(\chi^{2}(9)=10.015, p<.349\right)$. In terms of occupation, 84 were students $(12.7 \%), 517$ were working (78.4\%), 42 were unemployed (6.3\%), 6 were retired $(0.9 \%)$, and 10 did not respond to the question $(1.5 \%)$. Again, problem gambling severity was not significantly associated with occupation $\left(\chi^{2}(12)=11.376, p<.497\right)$. Regarding cohabitation, $11.5 \%$ of the bettors lived on their own, $55.8 \%$ with their partner, $3.6 \%$ with friends, $39.3 \%$ with their families, and $1.2 \%$ did not disclose any information. After controlling for familywise error by adjusting $p$ values using

Table 1 Socio-economic statistics for sports bettors $(N=659)$

\begin{tabular}{|c|c|c|c|c|c|c|}
\hline & $\begin{array}{l}\text { Non- } \\
\text { problem } \\
n=256 \\
(38.8 \%)\end{array}$ & $\begin{array}{l}\text { Low-risk } \\
n=175 \\
(26.6 \%)\end{array}$ & $\begin{array}{l}\text { Moderate- } \\
\text { risk } \\
n=102 \\
(15.5 \%)\end{array}$ & $\begin{array}{l}\text { Problem } \\
n=126 \\
(19.1 \%)\end{array}$ & $\chi^{2}(d f)$ & $p$ \\
\hline Age & $36.06(9.7)^{\mathrm{a}}$ & $34.28(9.93)$ & $34.04(11.35)$ & $35.13(10.01)$ & $4.692(3)$ & .196 \\
\hline \multicolumn{7}{|c|}{${ }^{-1}$} \\
\hline Female & $63(37.1 \%)^{\mathrm{b}}$ & $42(24.7 \%)$ & $25(14.7 \%)$ & $40(23.5 \%)$ & \multirow[t]{2}{*}{$2.902(3)$} & \multirow[t]{2}{*}{.407} \\
\hline Male & $193(39.5 \%)$ & $133(27.2 \%)$ & $77(15.7 \%)$ & $86(17.6 \%)$ & & \\
\hline \multicolumn{7}{|l|}{ Education } \\
\hline $\begin{array}{l}\text { Less than complete high } \\
\text { school }\end{array}$ & $1(20 \%)$ & $1(20 \%)$ & $1(20 \%)$ & $2(20 \%)$ & \multirow[t]{4}{*}{$10.015(9)$} & \multirow[t]{4}{*}{.349} \\
\hline Complete high school & $42(36.8 \%)$ & $35(30.7 \%)$ & $23(20.2 \%)$ & $14(12.3 \%)$ & & \\
\hline $\begin{array}{l}\text { Vocational or technical } \\
\text { education }\end{array}$ & $57(41 \%)$ & $31(22.3 \%)$ & $24(17.3 \%)$ & $27(19.4 \%)$ & & \\
\hline University education & $156(38.9 \%)$ & $108(26.9 \%)$ & $54(13.5 \%)$ & $83(20.7 \%)$ & & \\
\hline \multicolumn{7}{|l|}{ Living with } \\
\hline Alone & $39(51.3 \%)$ & $19(25 \%)$ & $8(10.5 \%)$ & $10(13.2 \%)$ & \multirow[t]{5}{*}{$27.210(12)$} & \multirow[t]{5}{*}{$.007 *$} \\
\hline Partner & $105(36 \%)$ & $74(25.3 \%)$ & $39(13.4 \%)$ & $74(25.3 \%)$ & & \\
\hline Friends & $5(20.8 \%)$ & $9(37.5 \%)$ & $3(12.5 \%)$ & $7(29.2 \%)$ & & \\
\hline Family (other than partner) & $104(40.2 \%)$ & $72(27.8 \%)$ & $50(19.3 \%)$ & $33(12.7 \%)$ & & \\
\hline Other & $3(37.5 \%)$ & $1(12.5 \%)$ & $2(25 \%)$ & $2(25 \%)$ & & \\
\hline \multicolumn{7}{|l|}{ Occupation } \\
\hline Studying & $25(29.8 \%)$ & $23(27.4 \%)$ & $18(21.4 \%)$ & $18(21.4 \%)$ & \multirow[t]{5}{*}{$11.376(12)$} & \multirow[t]{5}{*}{.497} \\
\hline Working & $210(40.6 \%)$ & $134(25.9 \%)$ & $73(14.1 \%)$ & $100(19.3 \%)$ & & \\
\hline Unemployed & $13(31 \%)$ & $15(35.7 \%)$ & $8(19 \%)$ & $6(14.3 \%)$ & & \\
\hline Retired & $4(66.7 \%)$ & $0(0 \%)$ & $1(16.7 \%)$ & $1(16.7 \%)$ & & \\
\hline Other & $4(40 \%)$ & $3(30 \%)$ & $2(20 \%)$ & $1(10 \%)$ & & \\
\hline
\end{tabular}


Bonferroni correction, a significant association was found between cohabitation and problem gambling categories $\left(\chi^{2}(12)=27.210, p<.007\right)$. Adjusted residuals in the contingency table with a $z$ score higher than 2 revealed that problem gamblers were much more likely to live only with their partner $(Z=3.6)$, whereas those living with their families were less likely to be problem gamblers $(Z=-3.4)$. Those who reported being students had higher percentages than expected of low, moderate, and problem gambling incidence, while those unemployed were underrepresented among all risk categories including problem gamblers. Nonetheless, none of these associations were found to be statistically significant $\left(\chi^{2}(12)=11.376, p=.497\right)$.

Unlike socio-economic data, the use of new structural characteristics greatly varied among individuals from different gambling severity groups. Table 2 shows the main findings for these variables. Problem gambling severity was positively associated with (i) how much participants discussed about betting with other people before placing bets, (ii) how often they use new online betting functionalities such as "cash out," and (iii) devoting more time to betting. All these associations were significant at the $p<.001$ level. Similarly, in-play betting was more prevalent among problem gamblers than among any other group $\left(\chi^{2}(3)=87.024, p<.001\right)$. Enjoying the watching of games more when a bet is in place also showed statistically significant differences between groups. Non-problem gamblers reported lower satisfaction $(M=3.19, \mathrm{SD}=1.21)$ than low-risk gamblers $(M=3.49, \mathrm{SD}=1.16)$, who in turn also showed less satisfaction than moderate-risk gamblers $(M=3.63, \mathrm{SD}=1.07)$. However, individuals within the problem gambling category reported lower levels than both moderate and lowrisk gamblers $(M=3.44, \mathrm{SD}=.90)$.

Having participated in fantasy sports during the last year (i.e., yes/no) was compared to problem gambling categories. The results showed that 127 out of 256 sports bettors (49.6\%) pertaining to the non-problem gambler group had participated in fantasy gaming. The proportion was only slightly higher for the low-risk problem gambling group (90 out of $175 ; 51.4 \%$ ), while the moderate-risk group scored considerably higher (63 out of 102; $61.7 \%)$. Nearly all sports bettors in the problem gambling category had engaged in fantasy gaming (119 out of $126 ; 94.4 \%$ ). These differences were found to be statistically significant $\left(\chi^{2}(3)=53.271, p<.001\right)$. Similarly, taken as continuous scales, a very significant correlation was found between scores on fantasy game participation (ranging from never in the past 12 months to always) and severity of problem gambling (range 1-27) (Spearman's rho $=.238, p<.001)$.

There was no clear pattern of locations preferred by bettors for gambling. Most bettors across every gambling severity category favored their home as their place of choice for betting $(75.11 \%)$. The workplace was only chosen by $2.42 \%$ of the sample, with inconclusive distribution between gambling severity categories. However, there were some indications that problem gamblers bet from work more often than other groups, because they represent in the current sample $31.3 \%$ of the gamblers, above the $19.1 \%$ expected according to their relative size within the sample. Approximately one in seven of bettors $(15.32 \%)$ reported gambling more frequently on the street than in any other place, which included both betting via mobile devices or in betting shops, while $7.13 \%$ of bettors reported gambling somewhere else. Nevertheless, no statistically significant association was found in the behavior of individuals between different groups $\left(\chi^{2}(9)=12.452, p=.189\right)$.

Concerning the devices or platforms used to gamble, online gambling was far more prevalent than offline gambling. The majority of bettors $(83.4 \%)$ chose computer, laptops, tablets, or mobile phones as their preferred way of gambling rather than going to a betting shop $(16.5 \%)$. However, such behavior varied greatly between gambling severity groups $\left(\chi^{2}(6)=\right.$ 


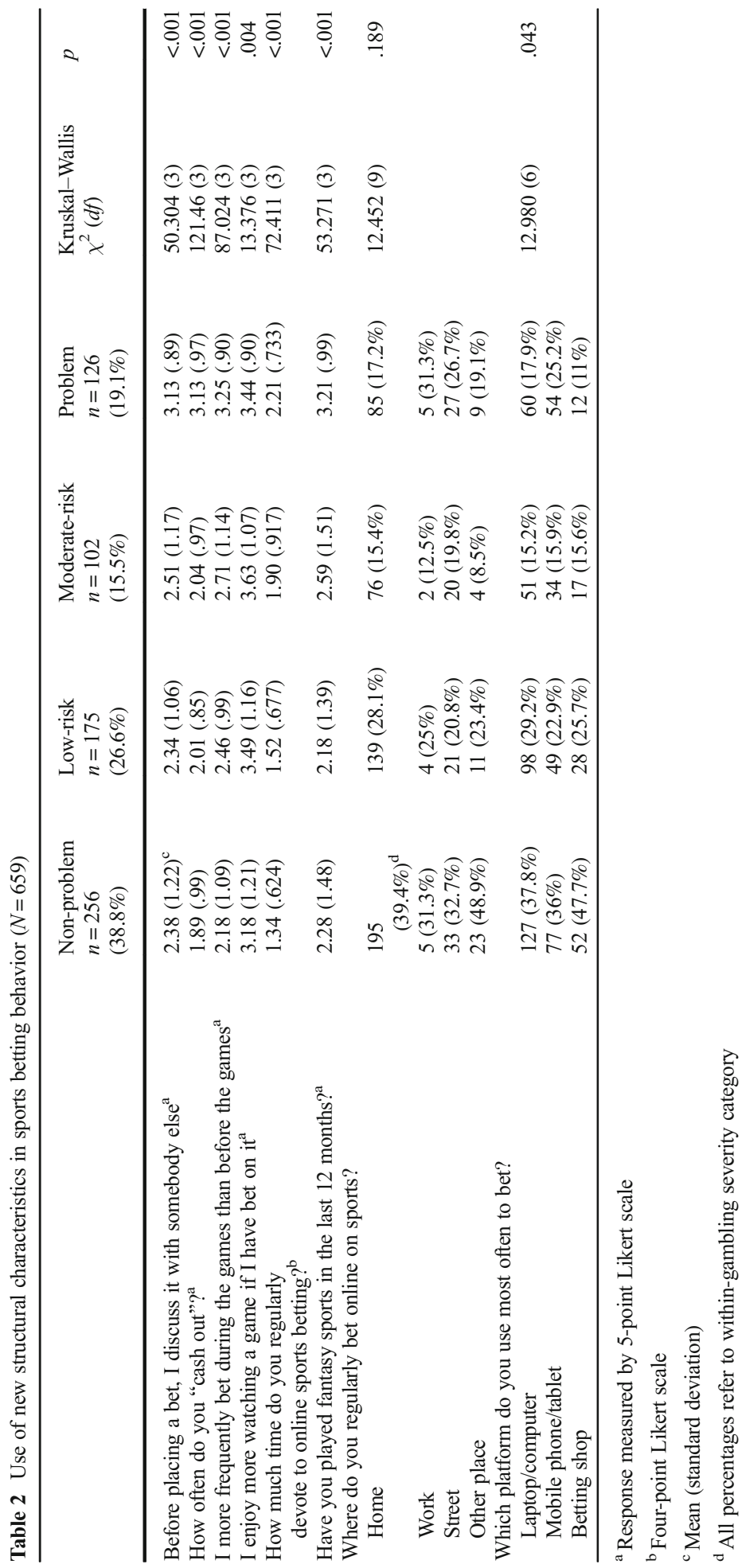


$12.980, p<.043)$. Online betting was reported by $90.47 \%$ of problem gamblers as their gambling preference, while it was slightly less favored by moderate-risk gamblers $(83.3 \%)$, low-risk gamblers (84\%), and non-problem gamblers (79.7\%). Consequently, the non-problem gambler category was overrepresented in the offline betting condition, amounting to $47.7 \%$ of bettors across all groups (and beyond the 38.8\% value expected for this particular group), while use of computer/laptops and mobile phones to gamble was lower within this group (37.8\% for computer and $36 \%$ for mobiles, both below the $38.8 \%$ baseline value). In contrast, offline betting was the form of gambling least favored by problem gamblers (11\%). In terms of mobile phone gambling, problem gamblers reported the highest preference for this method among any other group (25.2\%). This means that, within-group, $42.8 \%$ of problem gamblers primarily used their mobile phone to bet. Problem gamblers also reported below the average for computer/laptop betting (17.9\%, lower than the expected $19.1 \%)$.

\section{Discussion}

The present paper examined the demographic characteristics and betting behavior concerning new online structural characteristics among 659 sports bettors who had bet on sports during the previous 12 months, recruited via an online market research company. The study found that almost two-thirds of the sports bettors in the sample (61.2\%) showed some degree of risk in their gambling conduct, with just over one-third of the overall participants (34.6\%) reporting moderate-risk to problem gambling behavior. These results align reasonably well with recent Spanish prevalence studies. The most recent study - also using the PGSI-indicated a $0.3 \%$ of problem gambling prevalence and $0.9 \%$ of moderate-risk gambling in the country (GómezYáñez et al. 2017). However, among those who had reported gambling online in the past 2 months, the problem gambling rate increased to $17.3 \%$ (compared to $19.1 \%$ in the present study), moderate-risk gambling was $15.8 \%$ (15.5\% in the present study), and low-risk gambling was $33.3 \%$ (26.2\% in the present study). These numbers, in the context of Spain in 2016, translate into 96,000 individuals suffering moderate-risk and about 105,000 experiencing problems with online gambling.

A previous study from 2015 (i.e., Dirección General de Ordenación del Juego [DGOJ] 2016) conducted using an online survey targeting 500 individuals who had gambled online in the past 12 months reported findings are difficult to compare because the study used a completely different screening instrument to assess problem gambling was used, i.e., the National Opinion Research Center DSM Screen for Gambling Problems (NORC 1999). The prevalence rate of pathological gambling was reported to be $18.8 \%$, problem gambling $16.9 \%$, and risk gambling 32.8\% (DGOJ 2016). Therefore, although betting online was not a prerequisite for participating in the present study, the sports bettors' behavior reported here resembles that of other online gambler groups, with higher problem gambling rates than other land-based gamblers (Estévez et al. 2017).

The results also reflected a high prevalence of problem gambling among female bettors, showing that $31.7 \%$ of those in the problem gambling group were women. These results differ from those reported for an Australian sample of sports bettors in which problem gambling rates for males were significantly higher than for women (Hing et al. 2016) and follow-up studies where being male was a predictor of problem sports betting (Hing et al. 2017a). The findings in the present study also contradict the traditional gender imbalance found in most online gambling studies (Wood and Williams 2009) but not in the context of sports betting in 
particular, in which previous research with online gamblers playing on the bwin website reported non-significant differences between women and men (LaBrie et al. 2007).

Despite the fact that the results of the present study concerning gender and problem gambling did not have statistical significance, the large proportion of female bettors in the problem gambling category (23.5\% of females but only $17.6 \%$ of males) merits further research into an issue largely ignored (Hraba and Lee 1996; Järvinen-Tassopoulos 2016). Also, results from this sample on cohabitation and gambling severity showed greater risk for those living with their partner, which was similarly associated with being employed and therefore having a steady source of income. These results are partially at odds with previous studies in Spain examining risk factors among problem gamblers, which identified being single or divorced as the most risky cohabitation status (DGOJ 2017b).

Devoting time to gambling and discussing gambling-related topics was found to be associated with gambling severity. More importantly, in-play betting was especially associated with those being categorized as problem gamblers. Although higher gambling participation, and thus time devotion and conversation about it, is expected to be found among those with gambling problems, this does not explain why problem gamblers bet more heavily during games as opposed to before the games commenced. Problem gamblers are expected to gamble more in any given circumstance, including before and also during matches. However, the proportion of their gambling that they devote to in-play betting should be irrespective of their gambling participation and constant if compared to other individuals with lower PGSI scores. This is not the case in the present study. One interpretation could be that bettors who experience more problems with gambling also feel more inclined to consume impulsive, less planned, and immediate forms of gambling such as in-play betting, in which the bet cycles are brief (iGaming Business 2016) and the time elapsed since the placement of the bet until the reward (or lack thereof) is also shorter (Griffiths and Auer 2013; Lamont et al. 2016). The causal link between problem gambling and the use of products allowing immediate gambling rewards cannot be determined in a correlational study such as the present one. Nevertheless, the data suggest further research regarding the detrimental impact that structural characteristics of betting products might have on individuals developing gambling problems (Griffiths 1993; Parke and Griffiths 2007). In support of this interpretation, problem gamblers also reported higher use of "cash out" functionalities, which are a major component of in-play betting (Lopez-Gonzalez and Griffiths 2017).

The study also demonstrates, in the same vein as others carried out recently (Dwyer et al. 2017), the behavioral similarities of gambling and daily fantasy gaming. Engagement in fantasy sports and sports betting overlap greatly in the sample studied here, with greater involvement in fantasy games correlating to greater gambling problems. Engaging in fantasy gaming and watching live sports have been previously found to be associated (Drayer et al. 2010). The interaction in this study between a number of sports-related variables such as watching live sports, in-play betting, and fantasy and gambling involvement suggests that sports fandom might be playing a role in the cross-fertilization of different activities that are not inherently linked to sports. This adds to the idea that those sports fans with stronger and deeper ties to sport (e.g., team identification) might be more vulnerable to the promotions and marketing strategies of fantasy and gambling products addressed at them (Deans et al. 2016b; Lopez-Gonzalez et al. 2017b).

Despite all gambling severity groups reporting clear online gambling preference over offline alternatives, mobile phone betting distribution between gambling severity groups showed much higher prevalence among those with gambling problems. Similarly, those not 
experiencing gambling-related problems favored betting in offline gambling venues as their preferred gambling form. It is important to bear in mind that the question specifically asked for their preferred platform of choice to bet, so the results are not indicative of gamblers' use of each platform but of which one they used the most. Consequently, although it is likely that problem gamblers bet more than any other group both offline and online, and that they add new gambling forms as their condition worsens, their greater overall gambling activity cannot explain why they prefer betting via mobile phone. One way of interpreting this finding, in line with the in-play betting results, is that mobile betting allows for more instantaneous gambling, providing immediate universal access to betting, and simplifying betting procedures by implementing one-touch options or similar (Griffiths 2007; Deans et al. 2016b). This type of feature of mobile phone gambling is likely to affect the "schedule of reinforcement" (James et al. 2017), in this context, the timing and interval between play and reward (Griffiths and Auer 2013). Correspondingly, it has been noted that bookmakers promote mobile betting over other forms of gambling in their advertisements (Lopez-Gonzalez et al. 2017) by means of overemphasizing the illusion of control that gamblers perceive when using their smartphones to bet (Lopez-Gonzalez et al. 2017a).

\section{Limitations}

The present study is not without its limitations. The online sample is arguably overrepresentative of online gamblers and, in general, gamblers more familiarized with internet use. Consequently, participants' profile in the study was skewed towards young gamblers. This is likely to have had affected responses to questions regarding other online features such as inplay betting or the use of "cash outs." Also, respondents with university degrees were by far the largest educational category, causing further bias related to internet use. Another limitation has to do with the cross-sectional design of the study, which does not allow for clear causal implications between the variables, despite the significant differences found between the four different gambling severity groups. Finally, it is also possible that, among the individuals who received the survey request, those who exhibited a greater degree of involvement in betting activities were more interested in responding to the survey, and self-selected more often, resulting in a larger proportion of problem gamblers in the sample. Other limitations include the use of self-report data which are known to be subject to established biases such as social desirability and memory recall.

\section{Conclusion}

The present study is the first to examine a Spanish sample of sports bettors as a specific type of gamblers and explore their gambling in relation to sports betting-specific internet-based behaviors. Although the analyzed sample is not representative of the entire gambling population of the country, it has shown preliminary evidence that those engaging in sports betting could be suffering gambling-related problems in greater proportion than problem gambling prevalence studies typically suggest. Sports problem gamblers who engage in mobile betting appear to have become a distinctive attribute of their gambling behavior. Industry reports indicate that sports betting is the most popular form of online gambling in Europe, with continuous growth over the last decade (European Gaming and Betting Association 2016). With such rise of online betting participation, the present study highlights the new issues that 
are surfacing, particularly concerning the potentially detrimental effects of the interaction between sports viewing, live betting, and fantasy gaming. Regulation should be cognisant, especially considering the emotionally saturated context that sport identification generally entails as opposed to any other form of gambling, of the challenges of a market that encourages live rapid decision-making on events in which bettors are sentimentally partial.

Funding Information This work was supported by the Government of the Basque Country, Spain, under grant reference (Eusko Jaurlaritza, POS_2015_1_0062). This work has been additionally funded by the Spanish Organization of the Blind (ONCE, III International Award).

\section{Compliance with Ethical Standards}

Conflict of Interest Hibai Lopez-Gonzalez and Ana Estévez declare that they have no conflict of interest. Mark D. Griffiths declares that he has received funding for a number of research projects in the area of gambling education for young people, social responsibility in gambling, and gambling treatment from the Responsibility in Gambling Trust, a charitable body which funds its research program based on donations from the gambling industry. He also undertakes consultancy for various gaming companies in the area of social responsibility in gambling.

Informed Consent All procedures followed were in accordance with the ethical standards of the responsible committee on human experimentation (institutional and national) and with the Helsinki Declaration of 1975, as revised in 2000. Informed consent was obtained from all patients for being included in the study.

Open Access This article is distributed under the terms of the Creative Commons Attribution 4.0 International License (http://creativecommons.org/licenses/by/4.0/), which permits unrestricted use, distribution, and reproduction in any medium, provided you give appropriate credit to the original author(s) and the source, provide a link to the Creative Commons license, and indicate if changes were made.

\section{References}

d'Astous, A., \& Di Gaspero, M. (2015). Heuristic and analytic processing in online sports betting. Journal of Gambling Studies, 31(2), 455-470.

Deans, E. G., Thomas, S. L., Daube, M., Derevensky, J., \& Gordon, R. (2016a). Creating symbolic cultures of consumption: an analysis of the content of sports wagering advertisements in Australia. BMC Public Health, 16(1), 208.

Deans, E. G., Thomas, S. T., Daube, M., \& Derevensky, J. (2016b). I can sit on the beach and punt through my mobile phone: the influence of physical and online environments on the gambling risk behaviours of young men. Social Science Medicine, 166, 110-119 article.

Dirección General de Ordenación del Juego [DGOJ]. (2016). Estudio sobre prevalencia, comportamiento y características de los usuarios de juegos de azar en España 2015. Madrid: Ministerio de Hacienda y Administraciones Públicas.

Dirección General de Ordenación del Juego [DGOJ]. (2017a). Datos del mercado de juego online. Madrid: Ministerio de Hacienda y Administraciones Públicas.

Dirección General de Ordenación del Juego [DGOJ]. (2017b). Estudio y análisis de los factores de riesgo del trastorno de juego en población clínica española. Madrid: Ministerio de Hacienda y Administraciones Públicas.

Drayer, J., Shapiro, S. L., Dwyer, B., Morse, A. L., \& White, J. (2010). The effects of fantasy football participation on NFL consumption: a qualitative analysis. Sport Management Review, 13(2), 129-141. https://doi.org/10.1016/j.smr.2009.02.001.

Dwyer, B., Shapiro, S. L., \& Drayer, J. (2017). Daily fantasy football and self-reported problem behavior in the United States. Journal of Gambling Studies, 1-19.

Estévez, A., Rodríguez, R., Díaz, N., Granero, R., Mestre-Bach, G., Steward, T., ... Jiménez-Murcia, S. (2017). How do online sports gambling disorder patients compare with land-based patients?. Journal of Behavioral Addictions, 1-9. Epub ahead of print. https://doi.org/10.1556/2006.6.2017.067 
European Gaming \& Betting Association. (2016). Market reality. Brussels: European Gaming \& Betting Association.

Ferris, J., \& Wynne, H. (2001). The Canadian Problem Gambling Index: final report. Canadian Centre on Substance Abuse. Book, Ottawa, Ontario: Canadian Centre on Substance Abuse.

Gainsbury, S. (2014). AGRC discussion paper on interactive gambling. Melbourne: Australian Gambling Research Centre.

Gainsbury, S., \& Russell, A. (2015). Betting patterns for sports and races: a longitudinal analysis of online wagering in Australia. Journal of Gambling Studies, 31(1), 17-32.

Gainsbury, S., Russell, A., Wood, R., Hing, N., \& Blaszczynski, A. (2014). How risky is Internet gambling? A comparison of subgroups of internet gamblers based on problem gambling status. New Media \& Society, 17(6), 861-879.

Gainsbury, S., Russell, A., Hing, N., Wood, R., Lubman, D., \& Blaszczynski, A. (2015). How the Internet is changing gambling: findings from an Australian prevalence survey. Journal of Gambling Studies, 31(1), 115.

Gainsbury, S., King, D. L., Russell, A. M. T., Delfabbro, P., Derevensky, J., \& Hing, N. (2016). Exposure to and engagement with gambling marketing in social media: reported impacts on moderate-risk and problem gamblers. Psychology of Addictive Behaviors, 30(2), 270-276.

Gassmann, F., Emrich, E., \& Pierdzioch, C. (2017). Who bets on sports? Some further empirical evidence using German data. International Review for the Sociology of Sport, 52(4), 391-410.

Gómez-Yáñez, J., Cases-Méndez, J., Gusano Serrano, S., \& Lalanda Fernández, C. (2017). Percepción social sobre el juego de azar en España 2017. Madrid: IPOLGOB-UC3M.

Gordon, R., Gurrieri, L., \& Chapman, M. (2015). Broadening an understanding of problem gambling: the lifestyle consumption community of sports betting. Journal of Business Research, 68(10), 2164-2172.

Gray, H. M., LaPlante, D. A., \& Shaffer, H. J. (2012). Behavioral characteristics of Internet gamblers who trigger corporate responsible gambling interventions. Psychology of Addictive Behaviors, 26(3), 527-535.

Griffiths, M. D. (1993). Fruit machine gambling: the importance of structural characteristics. Journal of Gambling Studies, 9(2), 101-120.

Griffiths, M. D. (2007). Mobile phone gambling. In D. Taniar (Ed.), Encyclopedia of mobile computing and commerce (pp. 553-556). Pennsylvania: Information Science Reference.

Griffiths, M. D. (2017). The psychosocial impact of daily fantasy sports games. Casino and Gaming International, 30, 47-49.

Griffiths, M. D., \& Auer, M. (2013). The irrelevancy of game-type in the acquisition, development, and maintenance of problem gambling. Frontiers in Psychology, 3, 621.

Hing, N., Russell, A. M. T., Vitartas, P., \& Lamont, M. (2016). Demographic, behavioural and normative risk factors for gambling problems amongst sports bettors. Journal of Gambling Studies, 32(2), 625-641.

Hing, N., Russell, A. M., \& Browne, M. (2017a). Risk factors for gambling problems on online electronic gaming machines, race betting and sports betting. Frontiers in Psychology, 8, 779. https://doi.org/10.3389 /fpsyg.2017.00779.

Hing, N., Russell, A. M. T., Lamont, M., \& Vitartas, P. (2017b). Bet anywhere, anytime: an analysis of internet sports bettors' responses to gambling promotions during sports broadcasts by problem gambling severity. Journal of Gambling Studies. https://doi.org/10.1007/s10899-017-9671-9.

Holtgraves, T. (2009). Evaluating the problem gambling severity index. Journal of Gambling Studies, 25(1), $105-120$.

Hraba, J., \& Lee, G. (1996). Gender, gambling and problem gambling. Journal of Gambling Studies, 12(1), 83101.

Humphreys, B. R., \& Perez, L. (2012). Who bets on sports? Characteristics of sports bettors and the consequences of expanding sports betting opportunities. Estudios de Economía Aplicada, 30(2), 579-598.

iGaming Business. (2016). In-play focus 2016. London: Clarion Events Ltd..

James, R. J. E., O’Malley, C., \& Tunney, R. J. (2017). Understanding the psychology of mobile gambling: a behavioural synthesis. British Journal of Psychology, 108(3), 608-625.

Järvinen-Tassopoulos, J. (2016). Problem gambling and drinking among Finnish women. Nordic Studies on Alcohol and Drugs, 33(1), 27-42.

Jiménez-Murcia, S., Stinchfield, R., Fernández-Aranda, F., Santamaría, J. J., Penelo, E., Granero, R., et al. (2011). Are online pathological gamblers different from non-online pathological gamblers on demographics, gambling problem severity, psychopathology and personality characteristics? International Gambling Studies, 11(3), 325-337.

LaBrie, R., \& Shaffer, H. J. (2011). Identifying behavioral markers of disordered internet sports gambling. Addiction Research \& Theory, 19(1), 56-65. 
LaBrie, R., LaPlante, D. A., Nelson, S. E., Schumann, A., \& Shaffer, H. J. (2007). Assessing the playing field: a prospective longitudinal study of internet sports gambling behavior. Journal of Gambling Studies, 23(3), 347-362.

Lamont, M., Hing, N., \& Vitartas, P. (2016). Affective response to gambling promotions during televised sport: a qualitative analysis. Sport Management Review, 19(3), 319-331.

LaPlante, D., Schumann, A., LaBrie, R. A., \& Shaffer, H. J. (2008). Population trends in Internet sports gambling. Computers in Human Behavior, 24(5), 2399-2414.

LaPlante, D., Nelson, S. E., LaBrie, R. A., \& Shaffer, H. J. (2011). Disordered gambling, type of gambling and gambling involvement in the British Gambling Prevalence Survey 2007. European Journal of Public Health, 21(4), 532-537.

LaPlante, D., Nelson, S. E., \& Gray, H. M. (2014). Breadth and depth involvement: understanding Internet gambling involvement and its relationship to gambling problems. Psychology of Addictive Behaviors, 28(2), 396-403.

Lopez-Gonzalez, H., \& Griffiths, M. D. (2017). "Cashing out" in sports betting: implications for problem gambling and regulation. Gaming Law Review, 21(4), 323-326.

Lopez-Gonzalez, H., Guerrero-Solé, F., \& Griffiths, M. D. M. D. (2017). A content analysis of how "normal" sports betting behaviour is represented in gambling advertising. Addiction Research and Theory, 1-10. https://doi.org/10.1080/16066359.2017.1353082

Lopez-Gonzalez, H., Estévez, A., \& Griffiths, M. D. (2017a). Controlling the illusion of control: a grounded theory of sports betting advertising in the UK. International Gambling Studies, 1-17. https://doi.org/10.1080 $/ 14459795.2017 .1377747$

Lopez-Gonzalez, H., Estévez, A., \& Griffiths, M. D. (2017b). Marketing and advertising online sports betting: a problem gambling perspective. Journal of Sport \& Social Issues, 41(3), 256-272.

Martin, R. J., \& Nelson, S. (2014). Fantasy sports, real money: exploration of the relationship between fantasy sports participation and gambling-related problems. Addictive Behaviors, 39(10), 1377-1382.

Martin, R. J., Nelson, S. E., \& Gallucci, A. R. (2016). Game on: past year gambling, gambling-related problems, and fantasy sports gambling among college athletes and non-athletes. Journal of Gambling Studies, 32(2), 567-579.

McCormack, A., \& Griffiths, M. D. (2013). A scoping study of the structural and situational characteristics of internet gambling. International Journal of Cyber Behavior, Psychology and Learning, 3(1), $29-49$.

NORC (1999). Gambling Impact and Behavior Study. Report to the National Gambling Impact Study Commission. Chicago: National Opinion Research Center at the University of Chicago.

Nordmyr, J., Forsman, A. K., Wahlbeck, K., Björkqvist, K., \& Österman, K. (2014). Associations between problem gambling, socio-demographics, mental health factors and gambling type: sex differences among Finnish gamblers. International Gambling Studies, 14(1), 39-52.

Parke, J., \& Griffiths, M. D. (2007). The role of structural characteristics in gambling. In G. Smith, D. Hodgins, \& R. Williams (Eds.), Research and measurement issues in gambling studies (pp. 211-243). New York: Elsevier.

Pitt, H., Thomas, S. L., \& Bestman, A. (2016). Initiation, influence, and impact: adolescents and parents discuss the marketing of gambling products during Australian sporting matches. BMC Public Health, 16(1), 967.

Rodríguez, P., Humphreys, B. R., \& Simmons, R. (2017). Economics of sports betting. Northampton: Edward Elgar Publishing.

Rose, I. N. (2015). Are daily fantasy sports legal? Gaming Law Review and Economics, 19(5), 346-349.

Sproston, K., Hanley, C., Brook, K., Hing, N., \& Gainsbury, S. (2015). Marketing of sports betting and racing. Melbourne: Gambling Research Australia.

Wicker, P., \& Soebbing, B. P. (2013). Examining participation in sports betting in Germany. The Journal of Gambling Business and Economics, 6(3), 17-33.

Wood, R. T., \& Williams, R. J. (2009). Internet gambling: prevalence, patterns, problems, and policy options. Final report prepared for the Ontario Problem Gambling Research Centre. Guelph, Canada: Ontario Problem Gambling Research Centre.

Woolley, R. (2003). Mapping internet gambling: emerging modes of online participation in wagering and sports betting. International Gambling Studies, 3(1), 3-21. 